\title{
As transformações da memória: articulações entre Sigmund Freud e Eric Kandel [Ass transformações da memória]
}

\author{
Transformations of memory: Articulations between \\ Sigmund Freud and Eric Kandel [Transformations of memory] \\ Las transformaciones de la memoria: articulaciones entre Sigmund freud \\ y Eric Kandel [Las transformaciones de la memoria]
}

\author{
Graziele Luiza Barizon Scopel Gerbasi, Paulo José da Costa* \\ Universidade Estadual de Maringá
}

Doi: dx.doi.org/10.12804/apl33.01.2015.06

\section{Resumo}

O tema desta pesquisa é a memória e suastransformações, a partir da interlocução entre a psicanálise e as neurociências, representadas pelas obras de S. Freud e de E. Kandel, respectivamente. Seu objetivo é investigar quaissão as convergências entre as teorizações desses dois autores acerca das transformações da memória e, a partir disso, delinear possíveis articulações, acerca de alguns processos psíquicos e neurológicos que atuam em tais transformações. Para isso, são abordadas as noções de Freud sobre as retranscrições mnêmicas, as lembranças encobridoras e o Nachträglichkeit (aprèscoup) e também os mecanismos de consolidação e reconsolidação da memória de longo prazo descritos por Kandel. A principal convergência é o fato de que a memória é suscetível a (re) construções retroativamente.
Palavras-chave:Memória, psicanálise, neurociências

flbstract

The topic of this investigation is the memory and its transformations, exemplified by the dialogue between psychoanalysis and the neurosciences, represented by the works of S. Freud and E. Kandel, respectively. The goal is to investigate the points of convergence between the theorizations of these two authors about changes in memory and, from that, to outlines the possible connections, regarding some psychological and neurological processes that act in such transformations. For that, Freud's notions about mnemic retranscriptions, concealing memories and Nachträglichkeit (après-coup) and also the consolidation and reconsolidation mechanisms of long-term memory described by Kandel are addres-

* Graziele Luiza Barizon Scopel Gerbasi, Departamento de Psicologia, Universidade Estadual de Maringá; Paulo José da Costa, Departamento de Psicologia.

A correspondência relacionada com este artigo deve ser direcionada a Paulo José da Costa Paulo, Rua Campos Sales, 255 - ap. 102 - Zona 7 - CEP 87.020-080 Maringá-PR, Brasil. Correio eletrônico: pjcosta@uem.br

Para citar este artigo: Gerbasi, G. L. B. S., Costa, P. J. (2015). As transformações da memória: articulações entre Sigmund Freud e Eric Kandel (As transformações da Memória). Avances en Psicología Latinoamericana, 33(1), 77-89. doi: dx.doi.org/10.12804/ ap133.01.2015.06 
sed. The main convergence identified in the publications of these authors is the fact that the memory is susceptible to (re) constructions retroactively.

Keywords: Memory, psychoanalysis, neurosciences

\section{Resumen}

El tema de esta investigación es la memoria y sus transformaciones, a partir del diálogo entre psicoanálisis y neurociencias representadas por las obras de S. Freud y E. Kandel, respectivamente. El objetivo es investigar cuáles son las convergencias entre las teorizaciones de estos autores sobre las transformaciones de la memoria $\mathrm{y}$, a partir de esto, esbozar posibles articulaciones sobre algunos procesos psicológicos y neurológicos que actúan en tales transformaciones. Para ello, se abordan las nociones de Freud sobre las re-transcripciones mnémicas, los recuerdos encubridores y el Nachträglichkeit (aprèscoup) y también los mecanismos de consolidación y reconsolidación de la memoria a largo plazo descritos por Kandel. La principal convergencia es el hecho de que la memoria es susceptible a (re)construcciones retroactivamente.

Palabras clave: Memoria, psicoanálisis, neurociencias

Esta pesquisa teórica se situa no campo interdisciplinar entre a psicanálise e as neurociências, tendo como proposta identificar possíveis convergências entre as obras de Sigmund Freud e de Eric Kandel, a fim de elaborar articulações teóricas a respeito das transformações retroativas da memória. Tais transformações ocorrem à medida que o sujeito tem novas experiências. Portanto, parte-se do pressuposto de que as lembranças não correspondem de modo fidedigno aos acontecimentos, porque estão sujeitas a mudanças ao longo do tempo. Essa ideia está presente tanto na meta-psicologia freudiana, como nas noções de atos falhos, de retranscrições mnêmicas, de lembranças encobridoras, de Nachträglichkeit, quanto nas neurociências, devido às evidências de processos neurobiológicos envolvidos na consolidação e re- consolidação da memória de longo prazo, que lhe garantem maleabilidade.

Entretanto, a psicanálise e as neurociências têm bases epistemológicas diferentes. Enquanto a primeira produz conhecimento e evolui principalmente por meio da clínica psicanalítica, tendo sua validade reconhecida entre os pares, as neurociências seguem os paradigmas vigentes no campo das ciências naturais, como objetividade, reprodutibilidade, refutabilidade, entre outros, utilizando métodos experimentais para a comprovação de suas hipóteses. Embora exista essa divergência fundamental entre esses campos, evidenciada também nas obras de S. Freud e E. Kandel, ela não representa um obstáculo à interlocução proposta entre eles, porque o que se busca é uma cooperação interdisciplinar referente a um assunto de interesse comum, numa perspectiva de complementaridade. Portanto, não se trata de buscar confirmações ou refutações das suas construções teóricas, utilizando-se como critério de validade um pressuposto de um campo como referencial para o outro. A proposta desta pesquisa é tentar construir pontes que permitam trocas de saberes entre essas áreas, a fim de contribuir para a compreensão da memória.

A memória é um tema relevante, uma vez que é por meio de nossa história que nos constituímos como sujeitos, além de se mostrar adequado ao diálogo entre a psicanálise e as neurociências. As recordações representam a essência do material do trabalho analítico e os estudos neurocientíficos relacionados à memória já obtiveram muitos avanços, notadamente após o desenvolvimento das técnicas de neuroimagem e do conhecimento do genoma humano. A seleção das obras de Freud e Kandel justifica-se por seu reconhecimento no âmbito acadêmico mundial. Além disso, ambos expressam opiniões favoráveis a esse diálogo. Freud (1950/1986a) considerou que a psicanálise poderia se beneficiar com avanços da neurologia em prol de seu próprio desenvolvimento e aprimoramento, e Kandel (1999) argumenta em favor da cooperação da psicanálise com as neurociências, oferecendo 
subsídios teóricos para as pesquisas neste campo e desempenhando, desse modo, um papel ativo na construção de um modelo de investigação da mente. Assim, sugere que as duas áreas teriam seus próprios ganhos, sendo que os da psicanálise seriam a sua validação e o seu reconhecimento no meio científico por sua submissão aos seus métodos.

O principal objetivo deste trabalho é investigar a existência de convergências presentes na obra de S. Freud e de E. Kandel acerca da ideia de que ocorrem transformações da memória retroativamente. Seus objetivos específicos são: delinear a noção de que ocorrem transformações dos registros mnêmicos na obra de Freud incluindo as noções de retranscrição, de lembranças encobridoras e de Nachträglichkeit; esboçar a noção de memória e de suas transformações, segundo Kandel, principalmente em função do processo de reconsolidação; analisar as proposições acima e identificar elementos que possam contribuir para o estabelecimento de possíveis articulações entre essas teorias.

No decorrer deste artigo, são apresentados, primeiramente, um histórico das neurociências e dos estudos sobre a memória, bem como suas classificações e seus processos neurobiológicos. $\mathrm{Na}$ sequência, são delineadas algumas noções de Freud sobre as transformações mnêmicas. Então, é feita uma explanação sobre trabalhos atuais desenvolvidos na interface psicanálise/neurociências para, a partir daí, proceder-se à exposição das convergências identificadas e à elaboração das articulações possíveis entre eles. Por fim, são considerados os desdobramentos dessa interlocução relacionados à memória entendida como uma construção, suas implicações para a técnica psicanalítica e à temporalidade, segundo essa perspectiva interdisciplinar.

Sendo esta uma pesquisa teórica, foi realizado um amplo levantamento de publicações relacionadas ao tema no Brasil e no exterior, tanto de materiais impressos quanto daqueles disponíveis em bases de dados online, dos quais foi realizada a leitura e análise. Inúmeros estudos foram encontrados sobre assuntos afins aos desta pesquisa.
Existem publicações em que os autores se mostram favoráveis ao diálogo entre psicanálise e neurociências, incluindo aqueles que utilizam elementos de ambos os campos de forma complementar, enquanto outros são contrários a tal cooperação, por considerarem isso inviável ou desnecessário. Vários deles se dedicaram mais especificamente à memória, demonstrando a viabilidade da interlocução proposta neste estudo.

\section{As transformações da memória sob a perspectiva das neurociências}

Atualmente, no campo das neurociências são encontradas algumas classificações da memória. Uma delas se refere à sua duração, que pode ser de curto e de longo prazo. As memórias de curto prazo têm duração de uma a seis horas. Um exemplo é a memória de trabalho, que permite que o indivíduo mantenha uma conversa, dê seguimento a uma ação, enfim, que possa administrar sua realidade imediata. Neurobiologicamente, a memória de curta duração exige apenas a modificação de proteínas pré-existentes e da força das conexões sinápticas. Já a memória de longo prazo pode durar dias, meses ou anos. Seu processo de consolidação dura de três a oito horas e requer a síntese de proteínas e a formação de novas conexões neuronais. Esse é um período em que a memória ainda é lábil e sujeita a interferências de outros estímulos (Izquierdo, 2011; Kandel, 2001; Kandel, 2012; Mayford, Siegelbaum \& Kandel, 2012).

Outra classificação divide as memórias em implícitas ou não declarativas e explícitas ou declarativas. As memórias não declarativas são inconscientes, num sentido descritivo, e envolvem a aquisição de habilidades motoras e cognitivas resultantes da experiência, que se expressam por mudanças no comportamento. Porém, não são recordadas conscientemente e relatadas pelo indivíduo, embora seja possível construir conhecimento explícito acerca delas (Gazzaniga, Ivry \& Mangun, 2006; Lent, 2001; Kandel, Kupfermann \& Iversen, 
2003; Squire \& Kandel, 2003). O hipocampo desempenha um papel importante na consolidação da memória explícita, pois células ali presentes são suscetíveis à potenciação de longa duração (LTP sigla em inglês para long-term potentiation), que é um tipo de facilitação sináptica que aumenta sua efetividade (Gazzaniga et al., 2006; Kandel, 2003; Kandel, 2009b; Squire \& Kandel, 2003). O processo de consolidação está sujeito a influências, por exemplo, da atenção, do estado emocional, dos níveis de estresse e ansiedade, entre outros. Esses fatores exercem um efeito modulatório na aquisição da memória (Izquierdo, 2011; Lent, 2001).

As transformações, às quais a memória declarativa está sujeita, se tornam evidentes na sua evocação, momento em que ocorre sua reconsolidação. Durante esse processo, a memória entra em um estado de maleabilidade que permite sua edição, sendo possível a adição, subtração ou distorção de alguns de seus elementos. Isto oferece as bases para que suas transformações sejam consideradas tanto em seus aspectos cognitivos quanto neurobiológicos. Kandel (2009a) apresenta a ideia de que na recordação ocorre a reconstrução da memória que, portanto, é um processo criativo e não mera reprodução de algo imutável. Squire e Kandel (2003) referem que é possível que uma lembrança seja diferente daquilo que foi armazenado a princípio e que a recordação representa

um processo reconstrutivo, não uma espécie de 'registro em vídeo' literal do passado. No final, uma experiência de evocação pode ser tida como precisa e subjetivamente convincente quando é apenas uma aproximação do passado e não de uma reprodução exata (p. 86).

Esses autores dizem ainda que "o cenário mais provável é que novos episódios de armazenamento de informação esculpam de novo, e, continuamente, representações previamente existentes. $\mathrm{O}$ apagamento do velho pelo novo e, provavelmente, a própria passagem do tempo mudam o conteúdo da memória" (Squire \& Kandel, 2003, p. 89). Na obra em que Kandel foi convidado a escrever em função de ter ganhado o Prêmio Nobel, ele também aborda esse assunto:

evocar uma lembrança episodicamente —não importa o quanto ela seja importante — não é como olhar uma fotografia num álbum. A recordação é um processo criativo. Acredita-se que aquilo que a mente armazena é apenas uma porção nuclear da memória. Ao ser recordada, essa porção nuclear é então elaborada e reconstruída, com subtrações, adições, elaborações e distorções (Kandel, 2009a).

Ideia semelhante é encontrada em publicações de outros neurocientistas. Izquierdo (2011) afirma que o cérebro é capaz de armazenar, modificar e reverter a realidade ao mundo real de forma coerente e, acerca da evocação, escreve que "ao converter a realidade num complexo código de sinais elétricos e bioquímicos, os neurônios traduzem... Em cada tradução ocorrem perdas e mudanças... Porque, afinal, traduzir quer dizer transformar" (p. 22). Por sua vez, Damásio (2011) também aborda tais alterações da memória, destacando que:

Conforme as experiências vividas são reconstruídas e reencenadas, seja na reflexão consciente, seja no processamento inconsciente, sua substância é reavaliada e inevitavelmente rearranjada, modificada em menor ou maior grau no que respeita à sua composição factual e acompanhamento emocional. Alguns quadros da recordação são extirpados na sala de cortes da mente, outros são restaurados e realçados, e outros ainda são tão habilmente combinados por nossas necessidades ou pelo acaso que criam novas cenas nunca realmente ocorridas. É assim que, com o passar dos anos, nossa história é sutilmente reescrita (Damásio, 2011).

Esse fenômeno é possível graças ao processo de reconsolidação, como explica Kandel (2009b): 
a descoberta de que a memória precisa ser mantida ativamente levanta questões relacionadas à evocação e à modificação da memória através da reconsolidação, na qual a recordação de uma experiência aprendida transforma a memória num estado lábil, apenas para se tornar estável novamente com o tempo (p. 12752, tradução nossa, destaque nosso).

Kandel participou de vários estudos relacionados à reconsolidação, dentre eles um no qual investigou esse mecanismo em nível celular. Utilizou a lesma marinha Aplysia (Lee et al., 2012), e buscou esclarecer se as mesmas sinapses envolvidas na codificação da memória são desestabilizadas e reestabilizadas ou se esse processo envolve novas sinapses. Ele e seus colegas concluíram que as mesmas sinapses que armazenam a memória de longa duração são reconstruídas após a evocação.

A plasticidade neuronal evidenciada pelas pesquisas de Kandel sobre a memória constituem, segundo ele, as bases neurobiológicas da individualidade. Tendo em vista que à medida que o indivíduo tem novas experiências e há formação de novas conexões sinápticas, cada encéfalo se torna único. Kandel (2009a) escreve que a

plasticidade do sistema nervoso... é o mecanismo subjacente à aprendizagem e à memória de longo prazo. Consequentemente, uma vez que cada ser humano cresce num ambiente diferente e tem experiências diferentes, a arquitetura do cérebro de cada pessoa é única.

Kandel faz um convite à psicanálise para o diálogo e a cooperação. Ele argumenta que estudos realizados de forma complementar entre a psicanálise e as neurociências podem ser produtivos e beneficiar ambos os campos (Kandel, 1998; 1999). Este neurocientista reconhece o valor da clínica psicanalítica como método de tratamento e sugere que a psicanálise traga contribuições aos estudos que visam ao entendimento do funcionamento psíquico. Entretanto, questiona sua metodologia de pesquisa que, a seu ver, não deve se restringir à relação entre analista e analisando que se dá no setting analítico. Ele acredita que teorias e práticas psicanalíticas devem ser submetidas aos métodos empíricos das ciências naturais, a fim de ter sua validade reconhecida e ter seu campo de investigação ampliado e aprimorado, incorporando dispositivos que garantam rigor acadêmico e atendam às exigências institucionais de pesquisa.

Esta visão não é compartilhada pela maioria dos representantes do campo psicanalítico, salvo poucas exceções e aqueles que são da área de neuropsicanálise. Esta postura faz com que ele se torne alvo de críticas, principalmente por ser considerado reducionista, como também por conceber que todas as funções psíquicas são resultado do funcionamento cerebral. Contudo, isso não impede uma interlocução, de modo que conhecimentos provenientes dessas diferentes disciplinas sejam usados de maneira complementar em busca de uma maior compreensão da mente/cérebro em toda sua complexidade.

\section{As transformações da memória sob a perspectiva da psicanálise freudiana}

A memória é um assunto abrangente na obra de Freud por permear toda a metapsicologia que desenvolveu. Quando ele fala sobre o aparelho psíquico e suas instâncias, os atos falhos, as psicopatologias, entre tantos outros conceitos, traz implícita alguma noção sobre a memória. Contudo, o tema desta pesquisa está circunscrito às transformações que a memória sofre retroativamente, ou seja, ela é entendida como resultado de um processo de (re) construção. Por isso, vamos abordar apenas algumas ideias de Freud que contribuem para o entendimento desse aspecto das recordações.

Desde a obra Projeto para uma psicologia cientifica, escrita em 1895 e publicada décadas depois, Freud (1950/1986a) já esboça um aparelho fundamentalmente de memória e de linguagem. Este aparelho é composto de sistemas neuronais 
cujas funções são a percepção $(\varphi)$, a memória $(\psi)$ e a consciência $(\omega)$. O sistema perceptivo não oferece resistência aos estímulos por não contar com barreiras de contato e, por isso, não armazena informações. Por outro lado, o sistema de memória oferece resistência e, assim, origina registros mnêmicos. Por sua vez, a consciência requer um elemento qualitativo, sendo que as representações são os elementos que viabilizam o acesso a ela. A primeira tópica composta pelos sistemas consciente, pré-consciente e inconsciente é mais bem delineada somente no capítulo VII de Interpretação dos sonhos (Freud, 1900/1986k). É nesse texto que Freud apresenta o inconsciente como uma instância psíquica que transcende o sentido descritivo e que armazena os traços mnêmicos, que somente chegam à consciência após sofrerem certa modulação de sua excitação no pré-consciente. A capacidade do inconsciente de registrar de forma duradoura os traços mnêmicos é ilustrada por Freud (1925/2011) em Nota sobre o bloco mágico.

A Carta 52 é de especial interesse, porque nela Freud (1896/1986c) postula que ocorrem vários processos de transcrição no aparelho psíquico: "de tempos em tempos o material preexistente em traços mnêmicos experimenta um reordenamento segundo novos nexos, uma retranscrição" (p. 274, tradução nossa). O primeiro reordena as percepções, passando pelo inconsciente e pelo pré-consciente até o consciente, por meio de seu representante psíquico. Outro processo de transcrição acontece ao longo das sucessivas etapas da vida do sujeito, em que as suas experiências são traduzidas segundo as leis de funcionamento de cada período do desenvolvimento. Assim, Freud transita de um modelo de caráter mais econômico e topológico para um mais dinâmico e, ainda, introduz a ideia de que novas circunstâncias vividas pelo sujeito podem influenciar a reordenação dos seus registros mnêmicos. Dessa forma, a memória estaria sujeita a rearranjos à medida que cada pessoa tem novas experiências, as quais terão efeito sobre as (re) configurações de suas recordações.
Outra noção freudiana que ajuda a elucidar as alterações da memória é a de lembranças encobridoras. Ele explica o que são tais lembranças principalmente num texto de mesmo nome (Freud, 1899/1986j) e em A psicopatologia da vida cotidiana (Freud, 1901/19861). O autor se dedica à tentativa de elucidar as nítidas lembranças infantis de eventos aparentemente insignificantes. Ele percebe que se trata de experiências significativas que, justamente por representarem conflitos e gerarem desprazer, são encobertas por recordações mais amenas por via associativa. A princípio, ele destaca que cenas infantis encobrem eventos posteriores de conteúdo conflitivo (Freud, 1899/1986j). Posteriormente, ele considera que cenas infantis são encobertas por lembranças de fases mais tardias da vida do sujeito (Freud, 1901/19861), deixando em aberto a possibilidade de esse fenômeno ocorrer em ambos os sentidos temporais. Portanto, aquilo que é recordado é maleável e suscetível a reedições em função de experiências subsequentes. Esta concepção das lembranças infantis poderia ser estendida às de etapas posteriores, incluindo as da vida adulta e velhice, uma vez que é sempre possível a mobilização de conflitos em função da persistência do infantil na vida anímica e da atemporalidade do inconsciente.

No que diz respeito à reconstrução retroativa da memória destaca-se a ideia de Nachträglichkeit (après-coup ou a posteriori), a qual se encontra várias vezes ao longo da teoria freudiana, algumas delas nessa forma substantivada ou como adjetivo ou advérbio (nachträglich). O termo après-coup foi proposto inicialmente por Jacques Lacan e, posteriormente, desenvolvido por Jean Laplanche, como veremos. Roudinesco e Plon (1998, p. 32) a descrevem como "um processo de reorganização ou reinscrição pelo qual os acontecimentos traumáticos adquirem significação para o sujeito apenas num a posteriori, isto é, num contexto histórico e subjetivo posterior, que lhes confere uma nova significação". Por sua vez, Laplanche e Pontalis (2000) dizem o seguinte: "há experiên- 
cias, impressões, traços mnésicos que são ulteriormente remodelados em função de experiências novas, do acesso a outro grau de desenvolvimento" (p. 33).

A noção de Nachträglichkeit aparece desde o Projeto (Freud, 1950/1986a) no relato do caso Emma, no qual uma situação vivida pela paciente aos 8 anos de idade se tornou traumática somente num segundo momento, aos 12 anos, quanto ocorreu outro evento, associado ao primeiro por alguns elementos, numa época em que Emma já estava na puberdade e pôde ter outra compreensão dos fatos devido à maturação sexual. No Rascunho $K$ (Freud, 1896/1986b) e nas Cartas 59, 61 e 75 (Freud, 1897/1986d,e,g), o autor faz alusão ao efeito retardado que uma recordação pode ter e, assim, mobilizar defesas, em função de fantasias formadas a partir de fatos vivenciados e são compreendidas somente posteriormente. A ideia de que lembranças sexuais infantis exercem efeito retardado também aparece em $A$ sexualidade na etiologia das neuroses (Freud, 1898/1986i). Em Observações adicionais sobre as neuropsicoses de defesa, Freud (1896/1986h) considera inclusive que lembranças não patogênicas podem ser substituídas posteriormente (nachträglich) por serem incompatíveis com alterações do ego, como na paranoia.

O efeito de Nachträglichkeit também é considerado nos casos clínicos de Elisabeth Von R., nos Estudos sobre a histeria (Freud,1895/1985); no do Pequeno Hans - Análise de uma fobia em um menino de cinco anos (Freud, 1909/1986m), em que ele considera que um fato atual é compreendido à luz de um acontecimento anterior que gera efeitos sobre o primeiro; e no caso do Homem dos lobos (Freud, 1918/2010), onde aparece diversas vezes, explicando o surgimento dos sintomas do jovem russo. Ele volta a mencionar esse último caso em Análise terminável e interminável (Freud, 1937/1986n), referindo-se ao efeito retardado que resquícios de conteúdos patogênicos ainda exerciam anos após encerrar sua análise. Lembrando que em traduções inglesas Nachträglichkeit aparece como deferred action (ou ação diferida).

Laplanche (1999; 2006) traz importante contribuição para a compreensão do après-coup (Nachträglichkeit) na obra freudiana e para ampliação de seu conceito. Na concepção desse autor o aprèscoup supera a contraposição entre determinismo (o passado determina o presente e o futuro) e hermenêutica (ideias do presente reinterpretam e resignificam o passado). Em seu modelo tradutivo, no bojo de sua Teoria da Sedução Generalizada, apresenta a noção de que mensagens enigmáticas são transmitidas do adulto para a criança e demandam tradução. Essas mensagens são traduzidas e retraduzidas, numa direção temporal alternadamente retroativa e progressiva, segundo Laplanche. Esta visão subverte a linearidade temporal e concebe passado, presente e futuro como coexistentes e de influência mútua.

\section{A interlocução entre psicanálise e neurociências sobre as transformações da memória}

Vários aspectos da teoria metapsicológica de Freud relacionados às transformações da memória foram objeto de estudos que visaram sua correlação com descobertas neurocientíficas. Um exemplo é a pesquisa de Bocchi (2010) que propôs a relação entre a potenciação de longa duração (LTP) e a ideia de facilitação presente no Projeto, uma vez que ambas forjam vias nervosas. Centonze, Siracusano, Calabresi e Bernardi (2004) também consideram que a concepção sobre os neurônios $\psi$, que seriam os responsáveis pelo armazenamento da memória, foi um insight de Freud sobre o que mais tarde seria descrito como LTP. Centonze, Siracusano, Calabresi e Bernardi (2005a) retomam a correlação entre as noções de Freud sobre a memória com a LTP e incluem a plasticidade sináptica em sua discussão. Os mesmos autores (Centonze, Siracusano, Calabresi \& Bernardi, 2005b) abordam as bases neurobiológicas da eficácia psicote- 
rapêutica. Para tanto, consideram uma disfunção do processo de consolidação e reconsolidação da memória e da plasticidade associada à sua manutenção ou extinção. Eles postulam que a psicoterapia tem como objetivo a remoção das memórias implícitas mal adaptativas e plasticidade sináptica disfuncional, exercendo ação sobre tais processos neurobiológicos.

São possíveis, ainda, algumas articulações envolvendo os atos falhos e distorções da memória estudadas sob a perspectiva da psicologia cognitiva. Autores que se destacam neste campo são Schacter (2001) e Loftus (2003a, 2003b). O primeiro afirma que as memórias estão sujeitas a vieses, em função de emoções vividas e de conhecimentos adquiridos posteriormente aos fatos recordados. Schacter, Chiao e Mitchell (2003) referem que memórias implícitas podem exercer influência sobre experiências e ações atuais. Loftus (2001) sugere que imaginar um evento pode aumentar a confiança de que ele realmente ocorreu. Ela também desenvolveu pesquisas sobre a maleabilidade da memória e suas distorções, como em casos de testemunhas oculares. Além disso, pesquisou as falsas memórias que podem ser induzidas por informações incorretas, o que ficou conhecido como efeito da distorção de informação (Loftus, 2006).

Esses estudos sobre os vieses e distorções da memória também demonstram que ela está sujeita a transformações a partir de novas experiências do indivíduo. Essa noção é semelhante à ideia de Nachträglichkeit ou après-coup e, de acordo com os estudos apresentados, são fenômenos normais e possuem finalidade adaptativa. Isso pode oferecer subsídios para se considerar o après-coup de forma mais generalizada, como algo que ocorre no funcionamento psíquico comum, não ficando restrito a situações de trauma ou ao processo analítico. Desse modo, poderia ser concebido como um mecanismo atuante na vida mental que, a partir de experiências de maior conteúdo emocional ou conflitivo, poderia se intensificar e ter efeitos de maior amplitude.
O Nachträglichkeit representa uma noção freudiana que pode ser correlacionada com o processo de reconsolidação da memória, presente em publicações de Kandel, representando um ponto de convergência entre as obras desses autores. Portanto, o fato de que aquilo que é armazenado/inscrito no cérebro/mente sofre transformações retroativamente ao longo do tempo representa um possível consenso entre a psicanálise e as neurociências.

Bleichmar (2004) aborda as mudanças psíquicas produzidas pela análise. Ele postula que o efeito das interpretações se dá nas memórias implícitas, considerando as descobertas neurocientíficas sobre a sua labilidade que demonstram que "no momento da recordação, a memória entra num estado que tem sido designado como lábil, no qual a inscrição antiga é modificada pela experiência que está sendo vivida... no exato momento da recordação ocorre uma reinscrição da memória antiga" (p. 1393-1394, tradução nossa). Esse autor correlaciona este fenômeno ao après-coup: "esta reestruturação ocasiona a possibilidade de se adicionar elementos que não eram parte da circunstância original. $\mathrm{O}$ fenômeno da ação diferida [defered-action] (après-coup) descrita por Freud é solidamente corroborada pela pesquisa neurocientífica atual" (Bleichmar, 2004, p. 1394, tradução nossa). Este autor ainda destaca que a eficácia terapêutica depende de uma experiência relacional e afetiva, para que ocorra a reconfiguração do que está inscrito e, assim, uma efetiva transformação. Bleichmar (2010) considera o uso terapêutico da reconsolidação da memória e associa este mecanismo com o après-coup: "na verdade, os trabalhos atuais sobre a reconsolidação da memória, demonstrando que uma nova experiência muda o significado de uma experiência prévia e o integra em sua estrutura, corrobora a noção freudiana de Nachträglichkeit [defered action, après-coup]" (p. 1525-1526, tradução nossa).

É possível afirmar que Freud e Kandel apresentam concepções de individualidade e de singularidade com certas semelhanças em função do fato de ambos conceberem, respectivamente, um aparelho 
psíquico e neuronal que se (re) organiza à medida que o indivíduo tem novas vivências. Dessa forma, a constituição de cada sujeito passa por sua história de vida, por suas experiências afetivas, cognitivas, emocionais etc, que podem (re) configurar suas redes neuronais e (re) construir sua subjetividade. Isto permite que cada pessoa seja única e possa mudar.

A plasticidade neuronal e o fato de que a transmissão sináptica pode ser modulada pela experiência são considerados pontos de interlocução entre a psicanálise e as neurociências por Magistretti e Ansermet (2007). Eles dizem que "pelos mesmos mecanismos de plasticidade, através dos rearranjos dos traços inscritos, poderá se formar uma realidade inconsciente, que desempenhará um papel determinante na constituição do sujeito" (p. 139, tradução nossa). Também defendem que a reconsolidação cria uma descontinuidade entre a experiência e seu traço mnêmico de onde emerge o sujeito e o inconsciente. Tais autores ainda sustentam que as associações entre os traços ocorrem no après-coup e podem produzir uma nova realidade inconsciente, independente daquilo que constituiu os primeiros traços. "O inconsciente pode assim ser visto como descontinuidade, de onde se origina o sujeito em sua particularidade" (p. 142, tradução nossa). Segundo Arminjon, Ansermet e Magistretti (2010) “o sujeito produz traços de memória em vez de ser produzido por eles... tudo é registrado, mas tudo pode se desenvolver e mudar. Tudo é mantido, mas tudo é transformado: nós nunca usamos duas vezes o mesmo cérebro.” (p. 278, tradução nossa). Portanto, não somos biologicamente determinados, havendo a possibilidade de transformação e da existência da singularidade e da imprevisibilidade do sujeito.

A partir destas articulações teóricas, são pertinentes alguns desdobramentos relacionados às construções em análise e à temporalidade na interface entre psicanálise e neurociências. As construções fazem parte da técnica psicanalítica, junto com as interpretações. Freud (1937/1986o) explica que o analista deve ajudar o paciente a reconstruir suas recordações, baseado em seus sonhos, nos seus relatos por meio da associação livre, nos comportamentos que apresenta na relação transferencial. A confirmação das construções se dá por meio de novas associações que as complementem e elas são terapeuticamente eficazes, porque contêm fragmentos das experiências originais. Portanto, a memória entendida como uma construção tem implicações para a prática clínica e remete a questões relacionadas à verdade e à fantasia em análise, assunto abordado por Collins (2011) e também por autores que relacionam as construções em análise com o Nachträglichkeit, como Laverde-Rubio (2011), Bohleber (2007), Blanck-Cereijido (2006) e Faimberg $(2005 ; 2011)$.

Considerar as transformações às quais a memória está sujeita retroativamente traz implícita uma noção de temporalidade, marcada pelo Nachträglichkeit, que subverte a linearidade temporal. Segundo André (2008), o Nachträglichkeit rompe com a lógica que diferencia claramente passado e presente, atribuindo-lhes certa simultaneidade e poder de transformação, reinscrevendo o passado e reorganizando o psiquismo. Para o autor, a plasticidade oferecida pelo Nachträglichkeit abrange mesmo o recalcado, viabilizando a mudança psíquica e, assim, concebe uma temporalidade capaz de metamorfose. Marion (2012) também articula temporalidade e Nachträglichkeit, por sua vez oferecendo maior destaque para o período de latência entre o primeiro e o segundo tempo desse fenômeno, que seria a fase das elaborações psíquicas.

Sobre esse assunto são importantes as contribuições de Braier (2008) e Dahl (2010), que consideram a complementaridade entre presente $\mathrm{e}$ passado; Tutté (2004), para quem passado e futuro são reciprocamente modulados por seus significados; Birksted-Breen (2012), que faz uma leitura a partir da escola inglesa de psicanálise que privilegia o aqui-agora da sessão analítica; Azevedo (2011) que faz articulações com as neurociências; e, ainda, Gorender (2012), que resgata a relatividade do 
tempo para física moderna ao abordar o après-coup e as retranscrições da memória.

\section{Considerações finais}

Empreender a pesquisa sobre os vários estudos já realizados na interface entre psicanálise e neurociências proporcionou subsídios a favor da viabilidade e proficuidade dessa proposta, mas também ofereceu a perspectiva do quanto ainda é necessário pesquisar, dada a amplitude e a variedade dos temas possíveis. Demonstrou-se, ainda, que a memória representa um assunto pertinente a esse diálogo interdisciplinar.

Abordando mais especificamente a interlocução proposta entre S. Freud e E. Kandel, foram identificadas divergências entre eles, principalmente acerca da cientificidade da psicanálise, mas sobretudo algumas convergências acerca das transformações retroativas da memória, que lhe conferem caráter construtivo. Nesse percurso, foram contempladas ideias presentes desde as fases mais iniciais da metapsicologia freudiana, passando pelas retranscrições da memória, pelos atos falhos e lembranças encobridoras, até se chegar às construções em análise, abordando a técnica já em fase mais tardia. Também foram incluídos no diálogo alguns dados de pesquisas cognitivas sobre as distorções da memória. As convergências encontradas nas obras de Freud e Kandel permitiram articulações teóricas entre elementos neurobiológicos e psicanalíticos, como os processos de consolidação e reconsolidação da memória de longo prazo e o Nachträglichkeit. A plasticidade neuronal pode ser entendida como um correlato biológico da individualidade e da possibilidade de mudança psíquica, congregando a maleabilidade e a historicidade da subjetividade. Portanto, foi possível contribuir com o processo de construção de pontes entre a psicanálise e as neurociências que já vem sendo promovido por vários pesquisadores. Também se espera que outros mais possam contribuir com críticas e estudos posteriores, a fim de que esses caminhos se tornem mais seguros e levem a novos desenvolvimentos.

\section{Referências}

André, J. (2008). O acontecimento e a temporalidade: o après-coup no tratamento. Ide psicanálise e cultura, 31(47), 139-167.

Arminjon, M., Ansermet, F., \& Magistretti, P. (2010). The homeostatic psyche: Freudian theory and somatic markers. Journal of Physiology-Paris, 104, 272-278.

Azevedo, A. M. A. (2011). Algumas considerações sobre o tempo. Jornal de Psicanálise, 44(81), 67-84.

Birksted-Breen, D. (2012). Taking time: the tempo of psychoanalysis. The International Journal of Psychoanalysis, 93, 819-835.

Blanck-Cereijido, F. (2006). La memoria en el diván. Acta Poetica, 27(2), 43-63.

Bleichmar, H. (2004). Making conscious the unconscious in order to modify unconscious processing: some mechanisms of therapeutic change. The International Journal of Psychoanalysis, 85, 1379-1400.

Bleichmar, H. (2010). On: Memory in a labile state: therapeutic application. The International Journal of Psychoanalysis, 91, 1524-1526.

Bocchi, J. C. (2010). A psicanálise freudiana o e atual contexto cientifico da biologia da mente: uma discussão a partir das concepções sobre o ego. (Tese de Doutorado, Universidade Federal de São Carlos. São Carlos, SP, Brasil).

Bohleber, W. (2007). Recordação, trauma e memória coletiva: a luta pela recordação em psicanálise. Revista Brasileira de Psicanálise, 41(1), 154-175.

Braier, E. (2008). Puntualizaciones desde una relectura de la retroactividad (Nachträglichkeit; après-coup) en la obra de Freud. Intercanvis, $21,13-38$ 
Centonze, D., Siracusano, A., Calabresi, P., \& Bernardi, G. (2004). The Project for a Scientific Psychology (1895): a Freudian anticipation of LTP-memory connection theory. Brain Research Reviews, 46, 310-314.

Centonze, D., Siracusano, A., Calabresi, P., \& Bernardi, G. (2005a). Long-term potentiation and memory processes in the psychological works of Sigmund Freud and in the formation of neuropsychiatric symptoms. Neuroscience, 130, 559-565.

Centonze, D., Siracusano, A., Calabresi, P., \& Bernardi, G. (2005b). Removing pathogenic memories: a neurobiology of psychotherapy. Molecular Neurobiology, 32(2), 123-132.

Collins, S. (2011). On authenticity: The question of truth in construction and autobiography. The International Journal of Psychoanalysis, 92, 1391-1409.

Dahl, G. (2010). The two time vectors of Nachträglichkeit in the development of ego organization: significance of the concept for the symbolization of nameless traumas and anxieties. The International Journal of Psychoanalysis, 91, 727-744.

Faimberg, H. (2005). Après-coup. The International Journal of Psychoanalysis, 86, 1-6.

Faimberg, H. (2011). Alegato en favor de la ampliación del concepto de Nachträglichkeit. Revista de Psicoanálisis LXVIII(2/3), 347-364.

Freud, S. (1985). Señorita Elisabeth von R. In: J. Breuer \& S. Freud, Obras completas Sigmund Freud (Vol. 2, 2a ed., pp. 151-194). (Trad.: José Luis Etcheverry.) Buenos Aires: Amorrortu editores. (Original publicado em 1895).

Freud, S. (1986a). Proyecto de psicología. In: S. Freud, Obras completas Sigmund Freud (Vol. 1, 2a ed., pp. 323-463). (Trad.: José Luis Etcheverry). Buenos Aires: Amorrortu editores. (Original publicado em 1950).

Freud, S. (1986b). Manuscrito K. Las neurosis de defensa. (Un cuento de Navidad). In: S. Freud, Obras completas Sigmund Freud (Vol. 1, 2a ed., pp. 260-269). (Trad.: José Luis Etcheverry). Buenos Aires: Amorrortu editores. (Original publicado em 1896).

Freud, S. (1986c). Carta 52. In: S. Freud, Obras completas Sigmund Freud (Vol. 1, 2a ed., pp. 274-280). (Trad.: José Luis Etcheverry) Buenos Aires: Amorrortu editores. (Original publicado em 1896).

Freud, S. (1986d). Carta 59. In: S. Freud, Obras completas Sigmund Freud (Vol. 1, 2a ed., p. 285). (Trad.: José Luis Etcheverry.) Buenos Aires: Amorrortu editores. (Original publicado em 1897).

Freud, S. (1986e). Carta 61. In: S. Freud, Obras completas Sigmund Freud (Vol. 1, 2a ed., pp. 288-289). (Trad.: José Luis Etcheverry). Buenos Aires: Amorrortu editores. (Original publicado em 1897).

Freud, S. (1986f). Carta 66. In: S. Freud, Obras completas Sigmund Freud (Vol. 1, 2a ed., pp. 299-300). (Trad.: José Luis Etcheverry). Buenos Aires: Amorrortu editores. (Original publicado em 1897).

Freud, S. (1986g). Carta 75. In: S. Freud, Obras completas Sigmund Freud (Vol. 1, 2a ed., pp. 310313). (Trad.: José Luis Etcheverry.). Buenos Aires: Amorrortu editores. (Original publicado em 1897).

Freud, S. (1986h). Nuevas puntualizaciones sobre las neuropsicosis de defensa. In: S. Freud, Obras completas Sigmund Freud (Vol. 3, 2a ed., pp. 157-184). (Trad.: José Luis Etcheverry.). Buenos Aires: Amorrortu editores. (Original publicado em 1896)

Freud, S. (1986i). La sexualidad en la etiología de las neurosis. In: S. Freud, Obras completas Sigmund Freud (Vol. 3, 2a ed., pp. 251-276). (Trad.: José Luis Etcheverry.). Buenos Aires: Amorrortu editores. (Original publicado em 1898).

Freud, S. (1986j). Sobre los recuerdos encubridores. In: S. Freud, Obras completas Sigmund Freud 
(Vol. 03, 2a ed., pp. 291-315). (Trad.: José Luis Etcheverry). Buenos Aires: Amorrortu editores. (Original publicado em 1899).

Freud, S. (1986k). La interpretación de los sueños. In: S. Freud, Obras completas Sigmund Freud (Vol. 5, 2a ed., pp. 504-612). (Trad.: José Luis Etcheverry). Buenos Aires: Amorrortu editores. (Original publicado em 1900).

Freud, S. (19861). Psicopatología de la vida cotidiana. In: S. Freud, Obras completas Sigmund Freud. (Vol. 06, 2a ed.). (Trad.: José Luis Etcheverry). Buenos Aires: Amorrortu editores. (Original publicado em 1901).

Freud, S. (1986m). Análisis de la fobia de un niño de cinco años. In: S. Freud, Obras Completas Sigmund Freud (Vol. 10, 2a ed., pp. 01-118). (Trad.: José Luis Etcheverry.) Buenos Aires: Amorrortu editores. (Original publicado em 1909).

Freud, S. (1986n). Análisis terminable e interminable. In: S. Freud, Obras completas Sigmund Freud (Vol. 23, 2a ed., pp. 211-254). (Trad.: José Luis Etcheverry). Buenos Aires: Amorrortu editores. (Original publicado em 1937).

Freud, S. (19860). Construcciones en el análisis. In: S. Freud, Obras completas Sigmund Freud (Vol. 23, 2a ed., pp. 255-270). (Trad.: José Luis Etcheverry.) Buenos Aires: Amorrortu editores. (Original publicado em 1937).

Freud, S. (2010). História de uma neurose infantil ("O homem dos lobos"). In: S. Freud, Sigmund Freud Obras Completas (Vol. 14, pp. 13-160). (Trad.: Paulo César de Souza). São Paulo: Companhia das Letras. (Original publicado em 1918).

Freud, S. (2011). Nota sobre o bloco mágico. In: S. Freud, Sigmund Freud Obras Completas (Vol. 16, pp. 267-274). (Trad.: Paulo César de Souza). São Paulo: Companhia das Letras. (Original publicado em 1925).

Gazzaniga, M. S., Ivry, R. B., \& Mangun, G. R. (2006b). Aprendizado e memória. In: M. S. Gazzaniga, R. B. Ivry \& G. R. Mangun, Neuro- ciência cognitiva: a biologia da mente ( $2^{\mathrm{a}}$ ed., pp. 319-367). Porto Alegre: Artmed.

Gorender, M. E. (2012). Tempo e memória. Estudos de Psicanálise, 37, 103-108.

Izquierdo, I. (2011). Memória (2a ed.). Porto Alegre: Artmed.

Kandel, E. R. (1998). A New Intellectual Framework for Psychiatry. American Journal of Psychiatry, 155(4), 457-469.

Kandel, E. R. (1999). Biology and the Future of Psychoanalysis: A New Intellectual Framework for Psychiatry Revisited. Americam Journal of Psychiatry, 156(4), 505-523.

Kandel, E. R. (2001). The Molecular Biology of Memory Storage: a Dialogue Between Genes and Synapses. Science, 294, 1030-1038.

Kandel, E. R. (2003). Mecanismos celulares da aprendizagem e as bases biológicas da individualidade. In: E. R. Kandel, J. H Schwartz. \& T. M. Jessell, Princípios da neurociência (pp. 12471279). Barueri, SP: Manole.

Kandel, E. R., Kupfermann, I., \& Iversen, S. (2003). Aprendizagem e memória. In: E. R. Kandel, J. H. Schwartz, \& T. M. Jessell, Princípios da neurociência (4 ed., pp. 1227-1246). Barueri, SP: Manole.

Kandel, E. R. (2009a). Em busca da memória: o nascimento de uma nova ciência da mente. São Paulo: Companhia das Letras.

Kandel, E. R. (2009b). The biology of memory: a forty-year perspective. The Journal of Neuroscience, 29(41), 12748-12756.

Kandel, E. R. (2012). The molecular biology of memory: cAMP, PKA, CRE, CREB-1, CREB-2, and CPEB. Molecular Brain, 5(14).

Laplanche, J. (1999). Notes sur l'après-coup. In: J. Laplanche, Entre séduction et inspiration : l'homme (pp. 57-66). Paris: Quadrige/PUF.

Laplanche, J. (2006). Problématiques VI: l'aprèscoup. Paris: Quadrige/PUF.

Laplanche, J., \& Pontalis, J. B. (2000). Vocabulário de Psicanálise (3a ed.) São Paulo: Martins Fontes. 
Laverde-Rubio, E. (2011). Trauma y fantasía, su efecto ulterior (Après-coup). Psicoanálisis, XXIII(2), 69-82.

Lee, S.H., et al (2012). A cellular model of memory reconsolidation involves reactivation-induced destabilization and restabilization at the sensorimotor synapse in Aplysia. Proceedings of National Academy of Science, 109(35), 14200-14205.

Lent, R. (2001). Pessoas com história: as bases neurais da memória e da aprendizagem. In: Lent. R. Cem bilhões de neurônios: conceitos fundamentais de neurociência (pp. 587-617). São Paulo: Editora Atheneu.

Loftus, E. F. (2001). Imagining the past. The Psychologist, 14(11), 584-587.

Loftus, E. F. (2003a). Make-believe memories. American Psychologist, 58(11), 864-873.

Loftus, E. F. (2003b). Our changeable memories: legal and practical implications. Nature reviews / Neuroscience, 4, 231-234.

Loftus, E. F. (2006). Memórias fictícias. Lusíada. Psicologia, 3-4, 335-350.

\section{Recebido em: 2 de julho de 2014 fprovado em: 19 de setembro de 2014}

Magistretti, P., \& Ansermet, F. (2007). La plasticité neuronale : un nouveau paradigme entre neurosciences et psychanalyse. Psychiatrie Sciences Humaines Neurosciences, 5, 138-143.

Mayford, M., Siegelbaum, S. A., \& Kandel, E. R. (2012). Synapses and memory storage. Cold Spring Harbor Perspectives in Biology, 4, 1-14.

Roudinesco, E., \& Plon, M. (1998). Dicionário de psicanálise. Río de Janeiro: Zahar.

Schacter, D. L. (2001). The seven sins of memory: how the mind forgets and remembers. Boston: Houghton Mifflin Company.

Schacter, D. L., Chiao, J. Y., \& Mitchell, J. P. (2003). The seven sins of memory: the implications for the self. Annals of New York Academy of Science, 1001, 226-239.

Squire, L. R., \& Kandel, E. R. (2003). Memória: da mente às moléculas. Porto Alegre: Artmed.

Tutté, J. C. (2004). The concept of psychical trauma: a bridge in interdisciplinary space. The International Journal of Psychoanalysis, 85, 897-921. 
